\title{
Transcatheter aortic valve looking for low-risk patients: a post hoc analysis of SURTAVI keeps opening the door
}

\author{
$3=6$
6 \\ Rodrigo Bagur ${ }^{1,2 *}, \mathrm{MD}, \mathrm{PhD}, \mathrm{FAHA}$ \\ 1. London Health Sciences Centre, London, Ontario, Canada; 2. Keele Cardiovascular Research Group, Centre \\ for Prognosis Research, Institute of Primary Care and Health Sciences, Keele University, Stoke-on-Trent, United \\ Kingdom
}

Knock, knock. Who is there? Me, Ms. Transcatheter Aortic Valve looking for low-risk patients, can I come in? Okay... but we are not ready (yet). Well, I am coming...

The updated European ${ }^{1}$ and American ${ }^{2}$ guidelines for patients with valvular heart disease support transcatheter aortic valve implantation (TAVI) for patients who are at intermediate risk for surgical aortic valve replacement (SAVR), or who have other risk factors not captured by the preprocedural risk scores such as frailty, porcelain aorta, hostile chest/radiation ${ }^{1,2}$. While the American $^{2}$ guidelines place a class I recommendation for SAVR and a class IIa recommendation for TAVI, the European guidelines ${ }^{1}$ place a class I recommendation for TAVI, and stress the benefits of transfemoral access in elderly patients ${ }^{1}$.

Guidelines recommend SAVR as class I in patients at low risk (and who have no other risk factors not included in the scores) ${ }^{1,2}$. In this issue of EuroIntervention, Serruys and colleagues ${ }^{3}$ report the one-year outcomes of patients with a Society of Thoracic Surgeons (STS) score $<3 \%$ enrolled in the Surgical Replacement and Transcatheter Aortic Valve Implantation (SURTAVI) trial ${ }^{4}$.

Article, see page 877
Overall, SURTAVI showed that TAVI was statistically non-inferior to SAVR in intermediate-risk patients ${ }^{4}$. The present post hoc analysis risk-stratified patients (for clinical relevance) into three strata: STS $<3 \%$ (TAVI=131, SAVR=123), STS 3-5\% (TAVI=480, $\mathrm{SAVR}=405)$, and $\mathrm{STS} \geq 5 \% \quad(\mathrm{TAVI}=253, \mathrm{SAVR}=268)^{3}$. In the stratum of STS $<3 \%$, the primary outcome of all-cause death or disabling stroke was significantly lower in TAVI as compared to SAVR $(1.5 \%$ versus $6.5 \%, \mathrm{p}=0.042)$, whereas similar results were observed in the STS $3-5 \%$ and STS $\geq 5 \%$ strata. Likewise, no statistical significance was observed when analysing all-cause mortality or disabling stroke separately across the three strata. Importantly, lower-risk patients had more valve reintervention: STS $<3 \%$ (4.6\% versus $0.9 \%, \mathrm{p}=0.071)$, STS $3-5 \%$ (1.9\% versus $0.3 \%, \mathrm{p}=0.024)$, and STS $\geq 5 \%(0.8 \%$ versus $0.8 \%, \mathrm{p}=0.949)$.

\section{ARE LOWER-RISK PATIENTS THE SAME AS YOUNGER PATIENTS? PROBABLY, BUT NOT ALL}

The Nordic Aortic Valve Intervention (NOTION) trial was the first to randomise all-comer lower-risk patients $(n=276)$ to TAVI with the CoreValve ${ }^{\circledR}$ (Medtronic, Minneapolis, MN, USA) or $\mathrm{SAVR}^{5}$. The mean age was 79 years, mean STS score $3.0 \pm 1.7 \%$,

*Corresponding author: Division of Cardiology, London Health Sciences Centre, University Hospital, 339 Windermere Road, London, ON N6A 5A5, Canada.E-mail: rodrigobagur@yahoo.com 
and $82 \%$ of patients had an STS score $<4 \%{ }^{5}$. No differences were observed between TAVI and SAVR in the composite endpoint of all-cause mortality, stroke, myocardial infarction, or separately, at one year ${ }^{5}$, two years ${ }^{6}$, and five years (Thyregod HG. Five-Year Outcomes From the All-Comers Nordic Aortic Valve Intervention Randomized Clinical Trial in Patients with Severe Aortic Valve Stenosis. Presented at the American College of Cardiology Annual Scientific Session, 10-12 March, 2018; Orlando, FL, USA). At five years, new permanent pacemaker implantation (PPI) following TAVI trended to be associated with increased mortality $(\mathrm{p}=0.07)$, and $2.5 \%$ of TAVI patients required valve reintervention whereas none did with SAVR $(p=0.09)$. A subgroup analysis of patients with an STS score $\geq 4$ showed a marginal benefit $(p=0.05)$ in terms of mortality at five years after SAVR.

The preprocedural clinical risk profile of TAVI patients has been considerably decreasing over the years. The FRANCE-TAVI registry $^{7}$ showed that, in $2015,70 \%$ of the patients were at intermediate/low risk, among whom $30 \%$ were at low risk. The present post hoc analysis of SURTAVI shows favourable results in terms of the primary composite endpoint of all-cause death or disabling stroke at one year, from a large randomised cohort of patients at lower risk ${ }^{3}$. This study also highlights a considerable decrease of age among the three STS strata, with a mean age of 75 years in the STS score $<3 \%$ stratum as compared to 80 years and 82 years in the $3-5 \%$ and $\geq 5 \%$ strata, respectively. This is in line with the latest transcatheter valve therapy registry data showing that $>20 \%$ of patients were $<75$ years old ${ }^{8}$.

The continuous expansion of TAVI to lower-risk patients is already happening. In fact, many "healthy" octogenarians presenting with an STS score $<3 \%$ are being treated with TAVI without much hesitation. However, for younger patients, structural valve deterioration (SVD), bioprosthetic valve failure (BVF) and the need for valve reintervention ${ }^{9-11}$ are important issues when making an informed decision between TAVI and SAVR. As mentioned above, SURTAVI patients with an STS score of $<3 \%$ and those with scores between 3 and $5 \%$ had substantially higher rates of valve reintervention as early as one year. Although $84 \%$ of the patients received a CoreValve and $16 \%$ an Evolut ${ }^{\mathrm{TM}} \mathrm{R}$ (Medtronic), and a newer generation of TAVI devices has evolved since then, the need for valve reintervention was relatively low in the STS score $\geq 5$ stratum and showed similar rates to SAVR.

Anatomical features inherent to a patient's age, notably the common prevalence of bicuspid aortic valves in younger adults ${ }^{12}$, pose technical challenges that are prone to suboptimal results (e.g., significant paravalvular leakage) with TAVI. Moreover, with conflicting data thus far, the long-term impact of new PPI requirements in younger patients is unknown. Therefore, the decision to offer TAVI rather than SAVR to low-risk and young patients must be carefully weighed against life expectancy ${ }^{9}$, also bearing in mind the excellent results achieved with SAVR ${ }^{13}$ and its wellknown long-term durability ${ }^{14}$.

\section{ONGOING TRIALS EVALUATING LOW-RISK PATIENTS}

Randomised controlled trials are currently ongoing and have been designed to evaluate the safety and efficacy of TAVI versus SAVR in low-risk patients. The Medtronic Evolut TAVR trial (NCT02701283) includes patients with an STS score of $<3 \%$, and the Placement of Aortic Transcatheter Valves 3 (PARTNER 3) trial (NCT02675114) includes patients with an STS score $<4 \%$. The NOTION-2 trial (NCT02825134) includes patients with an STS score of $<4 \%$ but who are also $\leq 75$ years, hence this trial will provide important information regarding younger patients. The Randomized Trial of TAVI versus SAVR in Patients With Severe Aortic Valve Stenosis at Intermediate Risk of Mortality (DEDICATE), though not entirely low-risk, includes all-comers (STS score 2-6\%), and set its primary efficacy endpoint as overall survival at five years. Unlike the two industry-sponsored trials, the NOTION-2 and DEDICATE trials allow any type of device with a CE mark. The results of these four trials will also help to determine the very long-term (i.e., 10 years) durability of contemporaneous TAVI devices.

In summary, it is reasonable to proceed with TAVI in low-risk octogenarians and it might be reasonable to start considering it in patients $\geq 75$ years old, probably soon. However, in younger patients, it is possible that TAVI SVD will occur when the patient is still otherwise in good shape. TAVI-in-TAVI might be possible if the mechanism of BVF is stenosis, but it is unlikely to be solved if there is paravalvular leakage. Hence, beyond the safety of TAVI, its efficacy should also be seen in terms of long-term durability; thus, of major importance for younger patients at low risk. After the completion of low-risk trials, we might end up talking about TAVI in "all-comers". Then, all the proposed risk score stratifications might perhaps remain for statistical adjustments (only?) rather than for decision making.

\section{Conflict of interest statement}

The author has no conflicts of interest to declare.

\section{References}

1. Baumgartner H, Falk V, Bax JJ, De Bonis M, Hamm C, Holm PJ, Iung B, Lancellotti P, Lansac E, Rodriguez Munoz D, Rosenhek R, Sjögren J, Tornos Mas P, Vahanian A, Walther T, Wendler O, Windecker S, Zamorano JL; ESC Scientific Document Group. 2017 ESC/EACTS Guidelines for the management of valvular heart disease. Eur Heart J. 2017;38:2739-91.

2. Nishimura RA, Otto CM, Bonow RO, Carabello BA, Erwin JP 3rd, Fleisher LA, Jneid H, Mack MJ, McLeod CJ, O'Gara PT, Rigolin VH, Sundt TM 3rd, Thompson A. 2017 AHA/ACC Focused Update of the 2014 AHA/ACC Guideline for the Management of Patients With Valvular Heart Disease: A Report of the American College of Cardiology/American Heart Association Task Force on Clinical Practice Guidelines. J Am Coll Cardiol. 2017;70:252-89.

3. Serruys PW, Modolo R, Reardon M, Miyazaki Y, Windecker S, Popma J, Chang Y, Kleiman NS, Lilly S, Amrane H, Boonstra PW, Kappetein AP, Onuma Y, Sondergaard L, van Mieghem N. Oneyear outcomes of patients with severe aortic stenosis and an 
STS-PROM of less than three percent in the SURTAVI trial. EuroIntervention. 2018;14:877-83.

4. Reardon MJ, Van Mieghem NM, Popma JJ, Kleiman NS, Sondergaard L, Mumtaz M, Adams DH, Deeb GM, Maini B, Gada H, Chetcuti S, Gleason T, Heiser J, Lange R, Merhi W, Oh JK, Olsen PS, Piazza N, Williams M, Windecker S, Yakubov SJ, Grube E, Makkar R, Lee JS, Conte J, Vang E, Nguyen H, Chang Y, Mugglin AS, Serruys PW, Kappetein AP; SURTAVI Investigators. Surgical or Transcatheter Aortic-Valve Replacement in Intermediate-Risk Patients. N Engl J Med. 2017;376:1321-31.

5. Thyregod HG, Steinbrüchel DA, Ihlemann N, Nissen H, Kjeldsen BJ, Petursson P, Chang Y, Franzen OW, Engstrom T, Clemmensen P, Hansen PB, Andersen LW, Olsen PS, Sondergaard L. Transcatheter Versus Surgical Aortic Valve Replacement in Patients With Severe Aortic Valve Stenosis: 1-Year Results From the AllComers NOTION Randomized Clinical Trial. J Am Coll Cardiol. 2015;65:2184-94.

6. Sondergaard L, Steinbrüchel DA, Ihlemann N, Nissen H, Kjeldsen BJ, Petursson P, Ngo AT, Olsen NT, Chang Y, Franzen OW, Engstrom T, Clemmensen P, Olsen PS, Thyregod HG. Two-Year Outcomes in Patients With Severe Aortic Valve Stenosis Randomized to Transcatheter Versus Surgical Aortic Valve Replacement: The All-Comers Nordic Aortic Valve Intervention Randomized Clinical Trial. Circ Cardiovasc Interv. 2016 Jun;9(6).

7. Auffret V, Lefevre T, Van Belle E, Eltchaninoff H, Iung B, Koning R, Motreff P, Leprince P, Verhoye JP, Manigold T, Souteyrand G, Boulmier D, Joly P, Pinaud F, Himbert D, Collet JP, Rioufol G, Ghostine S, Bar O, Dibie A, Champagnac D, Leroux L, Collet F, Teiger E, Darremont O, Folliguet T, Leclercq F, Lhermusier T, Olhmann P, Huret B, Lorgis L, Drogoul L, Bertrand B, Spaulding C, Quilliet L, Cuisset T, Delomez M, Beygui F, Claudel JP, Hepp A, Jegou A, Gommeaux A, Mirode A, Christiaens L, Christophe C, Cassat C, Metz D, Mangin L, Isaaz K, Jacquemin L, Guyon P, Pouillot C, Makowski S, Bataille V, RodésCabau J, Gilard M, Le Breton H; FRANCE TAVI Investigators. Temporal Trends in Transcatheter Aortic Valve Replacement in
France: FRANCE 2 to FRANCE TAVI. J Am Coll Cardiol. 2017;70:42-55.

8. Grover FL, Vemulapalli S, Carroll JD, Edwards FH, Mack MJ, Thourani VH, Brindis RG, Shahian DM, Ruiz CE, Jacobs JP, Hanzel G, Bavaria JE, Tuzcu EM, Peterson ED, Fitzgerald S, Kourtis M, Michaels J, Christensen B, Seward WF, Hewitt K, Holmes DR Jr. 2016 Annual Report of The Society of Thoracic Surgeons/American College of Cardiology Transcatheter Valve Therapy Registry. J Am Coll Cardiol. 2017;69:1215-30.

9. Bagur R, Pibarot P, Otto CM. Importance of the valve durability-life expectancy ratio in selection of a prosthetic aortic valve. Heart. 2017;103:1756-9.

10. Foroutan F, Guyatt GH, Otto CM, Siemieniuk RA, Schandelmaier S, Agoritsas T, Vandvik PO, Bhagra S, Bagur R. Structural valve deterioration after transcatheter aortic valve implantation. Heart. 2017;103:1899-1905.

11. Bagur R, Webb JG. Standardising definitions for bioprosthetic structural valve deterioration and failure: the European avantgarde. EuroIntervention. 2018;13:e1744-7.

12. Roberts WC, Ko JM. Frequency by decades of unicuspid, bicuspid, and tricuspid aortic valves in adults having isolated aortic valve replacement for aortic stenosis, with or without associated aortic regurgitation. Circulation. 2005;111:920-5.

13. Thourani VH, Suri RM, Gunter RL, Sheng S, O’Brien SM, Ailawadi G, Szeto WY, Dewey TM, Guyton RA, Bavaria JE, Babaliaros V, Gammie JS, Svensson L, Williams M, Badhwar V, Mack MJ. Contemporary real-world outcomes of surgical aortic valve replacement in 141,905 low-risk, intermediate-risk, and highrisk patients. Ann Thorac Surg. 2015;99:55-61.

14. Foroutan F, Guyatt GH, O'Brien K, Bain E, Stein M, Bhagra S, Sit D, Kamran R, Chang Y, Devji T, Mir H, Manja V, Schofield T, Siemieniuk RA, Agoritsas T, Bagur R, Otto CM, Vandvik PO. Prognosis after surgical replacement with a bioprosthetic aortic valve in patients with severe symptomatic aortic stenosis: systematic review of observational studies. BMJ. 2016; 354:i5065. 